\title{
Journal of Nursing and Care
}

\section{Assessment of the "Post-Acute Care Discharge Scores” (PACD) [Translated from the Original Article in German Published in Pflegewissenschaft 2015; 11: 582-95]}

\section{Conca Antoinette*}

Nursing Development, Cantonal Hospital Aarau, Switzerland

${ }^{*}$ Corresponding author: Antoinette Conca, RN MNS, Nursing Development, Cantonal Hospital Aarau, Tellstrasse 25,CH-5001 Aarau, Switzerland, Tel: +41 (0)62 838 43 74; E-mail: antoinette.conca@ksa.ch

Received date: Aug 27, 2018; Accepted date: Nov 19, 2018; Published date: Nov 21, 2018

Copyright: $\odot 2018$ Antoinette C. This is an open-access article distributed under the terms of the Creative Commons Attribution License, which permits unrestricted use, distribution, and reproduction in any medium, provided the original author and source are credited.

\begin{abstract}
A systematic and early biopsychosocial assessment of older patients in acute care hospitals is necessary for a proactive and effective discharge plan in order to identify patients at risk for a care deficit after hospitalization. Our study aim was to adapt the, "Post Acute Care Discharge" (PACD) Scores developed in Geneva for use in the Cantonal Hospital of Aarau and evaluate as screening instruments in selected medical patients in a medical university clinic. Among 308 patients admitted from home with urinary tract infections, falls, syncope or heart failure day 1 PACD $\geq 8$ had a sensitivity of $90 \%$ and a specificity of $62 \%$ and day 3 PACD $\geq 8$ a sensitivity of $80 \%$ and a specificity of $60 \%$ to identify a nursing care deficit. The PACD is used as a screening instrument to identify patients at risk and therefore facilitate a structured, interdisciplinary and patient-centered analysis of the situation and discharge plan.
\end{abstract}

Keywords: Screening method; Post-acute care needs; Hospitalized medical patients

\section{Introduction}

In Switzerland, $17.2 \%$ of the total population comprises adults older than 65 years of age with an increasing tendency [1]. Living with one or more chronic diseases is common in older adults. Consequently, there is an increase in nursing care needs in this group of patients [2]. Patients with treatable medical conditions are usually admitted to acute hospitals if they have no family members to provide them with nursing care. Later during hospital stay, nursing problems often arise $[3,4]$. Simonet et al. [5] reported that the most frequent cause for delayed hospital discharge was the non-availability of a bed in a postacute care institution. According to Boutin-Foster et al. [6], 30\% of delayed hospital discharges were due to non-medical reasons. For example, when discharge to home is not possible, no free bed in a nursing home is available or delivery of nursing or medical aids is delayed. For inpatients with respiratory tract infections, nursing care reasons such as waiting for a free bed in a post-acute institution have become significantly more important [7]. Even in medically stable respiratory tract infection patients with a structured triage and discharge plan, organizational reasons were responsible in $50 \%$ of the cases for delayed discharge [8]. A prolonged hospital stay due to nursing and organizational reasons was evident in $42.7 \%$ of medically stable patients with decompensated heart failure [9]. In contrast to this, regarding discharge decision, physicians, nurses, patients and relatives give priority to medical reasons $[10,11]$.

Older patients who are hospitalized due to acute conditions often lose functional abilities and independency of Activities of Daily Living (ADL) $[3,12-14]$. Maintaining self-care abilities is therefore essential for the discharge plan and for preparing patients to get back to their former living situation. Moreover, half of the patients who were older than 70 years and were hospitalized with an acute medical condition were not able to recover to their baseline function one year after discharge [15]. They suffered from serious consequences such as admission to a nursing home or death. For this reason, patients with biopsychosocial risks should be early identified-preferably at hospital admission, in order to determine discharge and follow-up care needs.

The German Experts Standard on "discharge management in nursing" emphasized that early systematic assessment is required to estimate post-discharge care deficit of patients in order to suit their needs [16]. Moreover, the Austrian "Quality Standard for admission and discharge management"[17] concluded that the discharge planning should begin with the nursing anamnesis. Patients' and relatives' feeling of insecurity is usually due to the lack of professional post care. Furthermore, rehospitalization could be caused by the interruption of care. Bowles et al. [18] suggest an automatized decision-making assessment to identify patients with post-discharge care needs. A standardized assessment to identify patients with postdischarge care needs is also considered to be needed by Holland et al. [19]. To be successful, nurse-guided discharge planning requires multidisciplinary collaboration and communication with patients and their families $[16,20]$. A comprehensive arrangement of discharge and post care for older patients leads to better patient outcomes, decreases the rate of rehospitalization and shortens the length of hospital stay [21-23].

\section{Background}

\section{Predictors of post-acute care needs}

Campbell et al. [24] identify physical functioning, age, presence of geriatric problems, male gender and living alone as predictors of a discharge to a post-acute care institution. Rudberg et al. [25] investigated characteristics of patients admitted to a nursing home after hospital discharge. The authors found following determinants: 
older age, living alone and preexisting limitations in the ADL before hospitalization. Cornette et al. [26] outlined age, limited Instrumental Activities of Daily Living (IADL), cognitive deficiency, rate of fall in the last years and poor self-evaluation as the five risk factors which could be assessed at admission. A systematic review recognized older age, cognitive deficiency, difficulties with ADL and IADL before admission, and depression as the strongest predictors of functional decline [27].

The following factors remained constantly important in the various studies: older age, living alone, functional disability and preexisting limitations in the ADL respectively IADL prior the hospital admission [24-26].

\section{Assessment tools/Measurements}

Grosse Schlarmann et al. [28] reviewed the Self-Care Index (SPI), which was created based on the result-oriented nursing assessment, acute care $(\mathrm{ePA}-\mathrm{ac})$, as a screening tool to identify post-discharge nursing care deficit.

In a data analysis of 620 cases, the SPI showed with a cut-off $<32$ a sensitivity of $81 \%$ and a specificity of $94 \%$. However, the activities of the social workers as part of the nursing case management initiated with $\mathrm{SPI}<32$ were used as external validation criterion.

The BRASS (Blaylock Risk Assessment Screening Score)-Index is a further discharge planning instrument which is applied shortly after admission. It predicts the necessity of discharge planning and can therefore prevent problems and undetected post-discharge care needs. The original English BRASS Instrument was translated and tested for validity in the Netherlands by Mistiaen et al. [29]. The Index composes information about age, living situation/emotional support, functional and cognitive status, behavioral pattern, mobility, perceptional deficit, previous hospital stays and emergency consultations, medically active problems and medication use. The authors found that with a cut-off of 9 points, the BRASS-Index has a sensitivity of $76 \%$ and a specificity of $75 \%$ in detecting a discharge to a location other than home. When applied in rehabilitation $(n=104)$, the BRASS-Index was modified using Rasch analysis. In regard to reliability (0.78) and construct validity (correlation with FIM, $\mathrm{r}=-0.853$; $\mathrm{p}<0.001$; a higher risk of discharge to a nursing home at a Score of $12 \mathrm{RR}=2.1,95 \% \mathrm{CI}=1.7-2.5$ ), it shows a potential for further examination [30]. In a publication of an article 2010, Hoogerduijn et al. [31] compared the instruments Identification of Seniors at Risk (ISAR), Hospital Admission Risk Profile (HARP) and Care Complexity Prediction Instrument (COMPRI). The aim was to show the instrument which most precise identifies patients with a risk of functional disability. None of the instruments was satisfactorily able to provide a valid estimation of the addressed risk.

Boutin-Foster et al. [6] used a preexisting instrument of the social services and a literature research to generate the SWAAT (Shock Waves therapy and Arginine for Achilles Tendinopathy)-Score. It is supposed to identify patients with complicated social needs who require social services within 24 hours. The SWAAT reached a test-retest reliability of 0.7 , the determination coefficient was $\mathrm{r}^{2}=0.40(\mathrm{p}=0.05)$, the AUC (Area Under the Curve): 0.75 and the relationship between SWAAT and both the need for social services $(\mathrm{p}<0.001)$ and the duration of hospital stay was significant $(\mathrm{p}<0.001)$. Items of the SWAAT Scores are limited ability to walk, patient cannot be discharged to the former place of residence, has home health care services, needs additional help at home, needs help to leave the hospital and/or with medical visits, is confused at admission and lives alone.

The Post-Acute Care Discharge scores (PACD) were developed in Geneva to identify patients with post-acute care needs, to enable the discharge plan to be discussed during ward rounds [5]. Two models with significant predictors (PACD version day-1 and day-3) were calculated to predict a discharge to a post-acute care institution. Both versions (day-1 and day- 3 ) showed good predictive ability in medicinal patients (AUC: 0.81 and 0.82 respectively). Scores of $\geq 8$ PACD day 3 reached a sensitivity of $87 \%$ and a specificity of $63 \%$ [5]. The PACD includes information about medically active problems, the support situation at home and the age. Furthermore are questions integrated related to ADL/IADL which is very much in line with the Swiss nursing culture. The PACD is best applicable for a risk estimation of a post-acute care need after hospital discharge and an early assessment at Interdisciplinary Emergency Center (INZ), because the questions are related to the situation prior the admission [32].

\section{Aim of the Study}

The aim of phase two of the OPTIMA Project (Optimized Patient Transfer through Innovative Multidisciplinary Assessment) [33] was to locally test the applicability of the PACD and to analyse the PACD as screening instruments in order to identify potential improvements or modifications. In addition, we intended to clarify whether the ideal point of time for the application of PACD was within 24 hours on day- 1 or on day-3. The sensitivity and specificity of the Swiss-German modified PACD's should be validated to evaluate its applicability on all medicinal patients of the Cantonal Hospital of Aarau AG (KSA; a teaching hospital in the German-speaking Switzerland)

\section{Methods}

\section{Design}

For the purposes, a prospective observational design has been selected.

\section{Sample}

Patients' recruitment and data collection was carried out in the interdisciplinary emergency center and on the wards of the medical university clinic of the KSA. Around 6000 patients are admitted yearly to the department of internal medicine which has around 400 employees from various disciplines. Four prevalent diagnoses were selected and a sample of around 400 patients was aimed for (1 winter season).

Patients were consecutively included if they were more than 18 years old, diagnosed with heart failure, fall, syncope or urinary tract infection and were admitted to the emergency department. Patients with limited cognitive ability or inability to communicate in German were excluded from the study.

\section{Ethical considerations}

Within the framework of the OPTIMA project, the quality management project was approved by the ethics commission of the canton Aargau (EK AG 2010/029). The responsible physician informed the patients orally and in a written form about the quality management project. The ethical commission waived an informed consent because 
of the observational nature of the study and to avoid selection bias. An oral consent was obtained from the patients for the telephone interview one month after the first data collection.

\section{Instruments}

To estimate the risk of post-acute care needs, patients' living situation was assessed using the PACD (Version day-1 and day-3). The PACD Version day-1 includes 15 items (Figure 1):

\section{Number of medically active problems on admission \\ Do you live with someone, who can help you at home? OYes ONo}

Independent in all aspects at home

O Needs help with ... (in the last 2 weeks): $\square$ grooming

dressing shower $\square$ feeding

toileting $\square$ walking

\section{transferring}

travelling via car or public transportation $\square$ food or clothes shopping
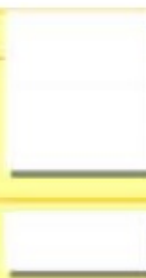

\section{Total Score}

\section{meal preparation}

$\square$ housework

$\square$ medication use

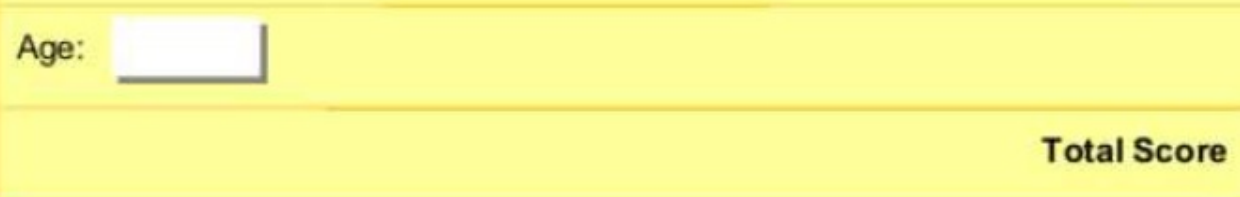

Figure 1: PACD day.

- The number of medically active problems on admission (1 point for each affected organ system). A medically active problem is one with therapeutic or diagnostic consequences for the actual treatment. One point is given for each organ system (based on the ICD 10 categories), whereas in some cases two points are given for diagnoses like respiratory tract infections with one point for the organ system and one point for the infectious disease. Are there more than one problem in the same organ system (for example, anemia, thrombopenia, leukopenia as a hematological problem) only one point is given (personal communication with Louis Simonet 17.05.2010; unpublished clinical documents 2010)

- Unavailability of a person in the same household who can provide help (4 points).

- Number of limitations in 12 ADLs or IADLs (grooming, dressing/ undressing, toileting, bathing or taking a shower, feeding, moving, transferring, travelling via car or public transportation, food or clothes shopping, meal preparation, housework, medication use (1 point per limitation).

- Age (1 point for each decade starting at the age of 60; for example, 2 points for someone between 70-79 years old).

"Internal hospital transfer", an item of the original score [5], occured rarely in the pilot study conducted in 2009/2010 in patients with respiratory tract infections [33] where it could not significantly predict the risk for post-acute care needs. Therefore, it was omitted in the KSA version.
In the original Geneva PACD day-1, no scoring was defined for the admission day model, because only the day-3 version score was implemented. The principle for point definition used by the authors for the scoring version day-3 [5] was adopted and applied on day-1 model. To define the point allocation, the standardized regression coefficients of day-1 model were compared with each other. Based on their value in relation to each other, proportional points per answer were defined (see explanation of day-3 scoring). Based on clinical considerations, the point definition for the age group was set to start from the age of 60 , where one risk point was given for each 10 years with a maximum of 5 points for patients older than 99 years.

- The cut-off for risk determination was set to $\geq 8$ points.

- The PACD version day-3 contained 5 items (Figure 2):

- The medically active problems at admission (1 point for each affected organ system)

- If the patient did not live with someone at home who could help (4 points)

- If the patient needed help with medication management before hospital admission (4 points)

- Dependency for bathing/taking a shower on day-3 (4 points)

- Dependency in transfers bed/chair on day-3 (4 points)

The scoring was adopted from Simonet et al. [5]. The justification of the point definition in the original PACD was as follows. The number of medically active problems, which is a continuous predictor in the 
logical regression model, showed a regression coefficient of 0.24 . This value was 4 times smaller than the standard regression coefficient of the other 4 predictors. Therefore, the 4 predictors were assigned 4 points and the medical problems 1 point pro problem [5].

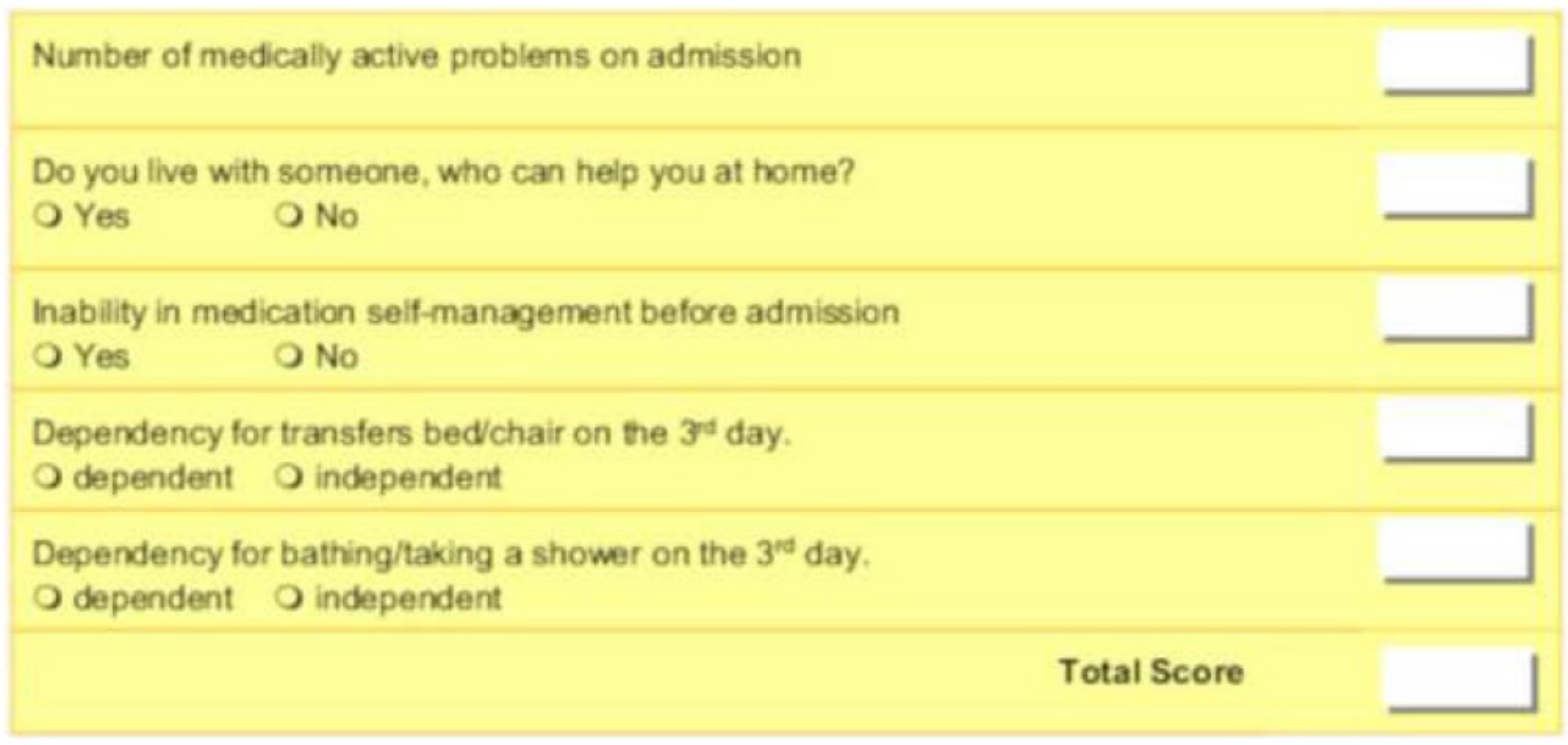

Figure 2: PACD day 3

The cut-off of risk determination for post-acute care need with PACD day-3 was adopted from the Geneva Version with $\geq 8$ points [5]. The scoring of both the PACD version day- 1 and day- 3 was verified on patients with respiratory tract infections as part of the pilot study OPTIMA I ( $\mathrm{n}=180)$ in the KSA. Both versions showed the best cut-off with 8 points showing an acceptable sensitivity and specificity (day-1: sensitivity $82 \%$, specificity $55 \%$, AUC: 0.80 ; day- 3 was primarily tested on the fourth day: sensitivity $69 \%$, specificity $76 \%$, AUC: 0.79$)[7,33]$. Consequently, the cut-off of PACD day- 1 was set to $\geq 8$ points. Based on the PACDs, patients were then divided in two or three categories. For the allocation of patients in two categories, low risk was assigned to scores $<8$ and a risk for post-acute care needs was assigned to scores $\geq 8$. On the other hand, for the allocation of patients to three categories, a low risk for post-acute care needs was assigned to $<8$, a raised risk to 8-15 and a very high risk to scores $>15$ points. A risk for post-acute care need was defined as discharge to a post-acute care facility (for example, temporary care, transient nursing care, health resort treatment, rehabilitation or nursing home).

\section{Data collection}

Data collection was carried out from September 2010 to September 2011. Data were collected from patients with the above-mentioned health problems. Physicians at the INZ collected clinical characteristics like confusion and the number of comorbidities. The health care team at the INZ (nurses/physicians) collected and evaluated the PACD day-1 (admission day). If this was not possible, the PACD scores were collected retrospectively by the study team members on the ward using the same questions. In this case, data were collected from interviewing the patient and from the clinical patient record. On the third day after admission, the nursing staff of the ward evaluated in addition to the information from the PACD day- 1 the patients' abilities for grooming and mobility. The SPI was measured as part of the standard nursing assessment within the first three days after admission. Patients' residence prior to admission (for example, home, transfer from another hospital, nursing or elderly home, etc.), discharge destination, nursing care complications or death of patients were collected from the electronic clinical patient records by the study team. Patient discharge home/to a geriatric apartment (with or without formal or informal ambulatory support) was differentiated from discharge to a post-acute care facility (temporarily or permanently).

\section{Data cleaning}

The consistency of the answers based on the same situation (point of admission or before) of day- 1 and day-3 scores was verified. Whereas the questioning on day- 1 and day- 3 was conducted by different persons and on two different locations (emergency room/ward), 94 pieces of information ( $10 \%$ of the cases) which should have been identical (as they were related to the situation before admission) were differently documented. All inconsistency was revised from the electronic clinical patients' records and verifiably modified. Any missing data were not replaced.

\section{Analysis of the diagnostic quality}

Knottnerus et al. [34] recommend the evaluation of the diagnostic estimations. They point out that the development and evaluation of the research-based diagnostic methods are less common than the evaluation of interventions in the evidence-based health care. To evaluate the diagnostic quality, a test objective should be defined. In this study, the test objective was to identify the risk of post-discharge transfer to a post-acute care facility.

The analysis aimed to illustrate the reliability of using the PACD on admission day and on the third hospitalization day to estimate the post-acute care needs.

The key figures are sensitivity, specificity and "Receiver Operating Characteristics" (ROC) with "Area Under the Curve" (AUC). An AUC 
test of 0.5 was considered useless, while an AUC test of 1.0 was the maximal score [34].

The primary endpoint of the study was the discharge to post-acute care facility. The calculations of the AUC ("Area Under the Curve", resulting from the ROC "Receiver Operating Curve" analysis) and the sensitivity and specificity of the PACD on day- 1 and day- 3 were based on this target value.

\section{Description measurement of the diagnostic tests PACD day-1 and 3}

The PACD should be implemented as a screening tool in the patient triage to identify every potential patient at risk of post-acute care needs who needs further assessment. Therefore, the requirement of high sensitivity and adequate specificity is justified. Scores of $>70 \%$ sensitivity and if possible $>70 \%$ specificity are recommended [35]. For the interpretation of the test question, the sensitivity is the most important measure followed by the AUC and the specificity. A very low specificity is considered unfavourable as it would lead to unnecessary extra assessment of the patients (additional effort), who do not need post-acute care transfer [34].

\section{ROC analysis and AUC}

ROC analysis was used to analyse the PACD score from day- 1 and day-3 with the target variable "transfer to an institution" and to determine the AUC (SPSS, 2007) [36]. The AUC evaluated the PACD day- 1 and day- 3 and the cut-offs were determined using the ROC analysis.

Patient characteristics were analysed descriptively using frequencies, percentages, median, mean and standard deviation based on the data types and variable distributions. Statistical analysis was performed using SPSS Version 20.0.

\section{Results}

\section{Sample characteristics}

A total of 371 patients with urinary tract infection, congestive heart failure, fall or syncope who were admitted to the INZ of the KSA and were then transferred to a medical university clinic ward were included in the study.

The average age of patients was 68.9 years; $43.9 \%$ were males. The majority lived at home with a partner/family (62.5\%). The number of patients who lived in a nursing home before admission varied depending on the diagnosis $(1.3 \%-16.5 \%)$. The sociodemographic data like age, gender and living situation are shown in Table 1. The medical characteristics of patients with congestive heart failure [9] and patients with urinary tract infections [37] were published previously.

\begin{tabular}{|c|c|c|c|c|c|}
\hline & $\begin{array}{l}\text { Patients } \\
(n=371)\end{array}$ & Syncope $(n=132)$ & $\begin{array}{l}\text { Urinary tract infection } \\
(n=127)\end{array}$ & $\begin{array}{l}\text { Congestive heart } \\
\text { failure }(n=75)\end{array}$ & Fall $(n=37)$ \\
\hline \multicolumn{6}{|l|}{ Sociodemographic characteristics } \\
\hline \multicolumn{6}{|l|}{ Gender } \\
\hline Male, number (\%) & $163(43.9 \%)$ & $71(53.8 \%)$ & $34(26.8 \%)$ & $43(57.3 \%)$ & $15(40.5 \%)$ \\
\hline Age mean; median & $68.9 ; 74.6$ & $65.8 ; 72.2$ & $61.8 ; 67.9$ & $79.8 ; 81.5$ & $82.1 ; 84.0$ \\
\hline (SD) & $( \pm 19.7)$ & $( \pm 20.6)$ & $( \pm 20.8)$ & $( \pm 8.75)$ & $( \pm 10.9)$ \\
\hline \multicolumn{6}{|l|}{ Living Situation, number (\%) } \\
\hline Living alone & $103(28.2 \%)$ & $40(30.3 \%)$ & $19(15.7 \%)$ & $28(37.3 \%)$ & $16(43.2 \%)$ \\
\hline Living with partner/family & $228(62.5 \%)$ & $90(68.2 \%)$ & $79(65.3 \%)$ & $44(58.7 \%)$ & $15(40.5 \%)$ \\
\hline Geriatric and nursing home & $27(7.4 \%)$ & $2(1.5 \%)$ & $20(16.5 \%)$ & $1(1.3 \%)$ & $4(10.8 \%)$ \\
\hline Another location, eg. geriatric apartment & $7(1.9 \%)$ & - & $3(2.5 \%)$ & $2(2.7 \%)$ & $2(5.4 \%)$ \\
\hline
\end{tabular}

Table 1: Sociodemographic characteristics.

$71.1 \%$ of patients reported the availability of someone who could help within the household (Table 2). The results showed the extent to which patients required help with the IADL within two weeks before admission. Patients showed an average of $2.8(\mathrm{SD} \pm 4.0)$ restrictions in the ADL/IADL and the majority of patients showed no restrictions before admission (median 0).

Patients with congestive heart failure and falls were older, lived more alone at home and required more help before hospital admission. Moreover, patients with urinary tract infections were mostly females and lived in nursing or elderly homes before admission.
The number of medically active problems at admission to the INZ was a median of 2 . Nursing complications were observed in $18.4 \%$ of the patients and $4.9 \%$ of patients died during hospitalization (Table 3 ). The collected data on day-3 showed that $55.3 \%$ of the patients were dependent with bathing or taking a shower and $31.8 \%$ needed help with transferring. Consequently, fall patients were the most restricted in this regard. This was supported by the first estimation of the SPI results. 
Citation: Antoinette C (2018) Assessment of the "Post-Acute Care Discharge Scores"(PACD) [Translated from the Original Article in German Published in Pflegewissenschaft 2015; 11: 582-95]. J Nurs Care 7: 468. doi:10.4172/2167-1168.1000468

Page 6 of 11

\begin{tabular}{|c|c|c|c|c|c|}
\hline & $\begin{array}{l}\text { Patients } \quad \text { total } \\
(n=371)\end{array}$ & $\begin{array}{l}\text { Syncope } \\
(n=132)\end{array}$ & $\begin{array}{l}\text { Urinary } \\
(n=127)\end{array}$ tract infection & $\begin{array}{l}\text { Congestive heart } \\
\text { failure }(n=75)\end{array}$ & Fall $(n=37)$ \\
\hline $\begin{array}{l}\text { Living with a person who can provide help, } \\
\text { number }(\%)\end{array}$ & $256(71.1 \%)$ & $90(69.8 \%)$ & $107(87.0 \%)$ & $47(64.4 \%)$ & $12(34.3 \%)$ \\
\hline \multicolumn{6}{|c|}{ Formal help in the last two weeks before admission, number (\%) } \\
\hline $\begin{array}{l}\text { Nursing care at home, housework with nursing } \\
\text { care }\end{array}$ & $77(21.2 \%)$ & $11(8.3 \%)$ & $29(24.0 \%)$ & $23(31.1 \%)$ & $14(37.8 \%)$ \\
\hline \multicolumn{6}{|c|}{ Informal help in the last two weeks before admission, number (\%) } \\
\hline Help from family, neighbors, friends & $80(22.0 \%)$ & $21(15.9 \%)$ & $25(20.7 \%)$ & $25(33.8 \%)$ & $9(24.3 \%)$ \\
\hline \multicolumn{6}{|c|}{ Needed help before admission to the hospital with: number (\%) } \\
\hline Grooming & $90(25.0 \%)$ & $15(11.6 \%)$ & $39(31.7 \%)$ & $21(28.8 \%)$ & $15(42.9 \%)$ \\
\hline Dressing & $73(20.3 \%)$ & $13(10.1 \%)$ & $28(22.8 \%)$ & $19(26.0 \%)$ & $13(37.1 \%)$ \\
\hline Toileting & $51(14.2 \%)$ & $7(5.4 \%)$ & $25(20.3 \%)$ & $12(16.4 \%)$ & $7(20.0 \%)$ \\
\hline Bathing or taking a shower & $94(26.1 \%)$ & $16(12.4 \%)$ & $40(32.5 \%)$ & $23(31.5 \%)$ & $15(42.9 \%)$ \\
\hline Feeding & $32(8.9 \%)$ & $5(3.9 \%)$ & $17(13.8 \%)$ & $5(6.8 \%)$ & $5(14.3 \%)$ \\
\hline Walking & $54(15.0 \%)$ & $6(4.7 \%)$ & $28(22.8 \%)$ & $13(17.8 \%)$ & $7(20.0 \%)$ \\
\hline Transferring & $46(12.8 \%)$ & $6(4.7 \%)$ & $25(20.3 \%)$ & $10(13.7 \%)$ & $5(14.3 \%)$ \\
\hline Travelling via car or public transportation & $99(27.5 \%)$ & $18(14.0 \%)$ & $40(32.5 \%)$ & $27(37.0 \%)$ & $14(40.0 \%)$ \\
\hline Food or clothes shopping & $116(32.2 \%)$ & $20(15.5 \%)$ & $44(35.8 \%)$ & $33(45.2 \%)$ & $19(54.3 \%)$ \\
\hline Meal preparation & $107(29.7 \%)$ & $20(15.5 \%)$ & $41(33.3 \%)$ & $27(37.0 \%)$ & $19(54.3 \%)$ \\
\hline Housework & $132(36.7 \%)$ & $25(19.4 \%)$ & $48(39.0 \%)$ & $36(49.3 \%)$ & $23(65.7 \%)$ \\
\hline Medication use & $100(27.8 \%)$ & $17(13.2 \%)$ & $43(35.0 \%)$ & $24(32.9 \%)$ & $16(45.7 \%)$ \\
\hline Number of limited & $2.8 ; 0.0$ & $1.3 ; 0.0$ & $3.4 ; 0.0$ & $3.4 ; 2.0$ & $4.5 ; 4.0$ \\
\hline ADL /IADL; mean; median (SD) & $( \pm 4.0)$ & $( \pm 2.9)$ & $( \pm 4.5)$ & $( \pm 3.9)$ & $( \pm 4.2)$ \\
\hline
\end{tabular}

Table 2: Availability and need for help prior to hospital admission; total patients.

\begin{tabular}{|c|c|c|c|c|c|}
\hline & $\begin{array}{l}\text { Patients total } \\
(n=371)\end{array}$ & $\begin{array}{l}\text { Syncope } \\
(n=132)\end{array}$ & $\begin{array}{l}\text { Urinary tract infection } \\
(n=127)\end{array}$ & $\begin{array}{l}\text { Congestive heart } \\
\text { failure } \\
(n=75)\end{array}$ & $\begin{array}{l}\text { Fall } \\
(n=37)\end{array}$ \\
\hline \multicolumn{6}{|l|}{ Clinical Characteristics } \\
\hline \multicolumn{6}{|l|}{ Hospital Status, number (\%) } \\
\hline Ambulatory & $90(24.3 \%)$ & $56(42.4 \%)$ & $29(22.8 \%)$ & $2(2.7 \%)$ & $3(8.1 \%)$ \\
\hline Inpatient & $281(75.7 \%)$ & $76(57.6 \%)$ & $98(77.2 \%)$ & $73(97.3 \%)$ & $34(91.9 \%)$ \\
\hline $\begin{array}{l}\text { Number of medically active problems at } \\
\text { admission; Mean; } \\
\text { Median (SD) }\end{array}$ & $\begin{array}{l}2.6 ; 2.0 \\
( \pm 1.4)\end{array}$ & $2.1 ; 2.0( \pm 1.4)$ & $\begin{array}{l}2.9 ; 3.0 \\
( \pm 1.2)\end{array}$ & $\begin{array}{l}2.6 ; 2.0 \\
( \pm 1.3)\end{array}$ & $3.5 ; 3.0( \pm 1.6)$ \\
\hline $\begin{array}{l}\text { Self-Care Index (SPI) Day 1-3; Mean; } \\
\text { Median (SD) }\end{array}$ & $\begin{array}{l}34.2 ; 38.0 \\
( \pm 7.6)\end{array}$ & $\begin{array}{l}37.9 ; 40.0 \quad( \pm \\
3.7)\end{array}$ & $\begin{array}{l}32.1 ; 37.0 \\
( \pm 9.2)\end{array}$ & $\begin{array}{l}32.8 ; 35.0 \\
( \pm 7.7)\end{array}$ & $30.2 ; 30.5( \pm 6.5)$ \\
\hline $\begin{array}{l}\text { Charlson Comorbidity Index; Mean; Median } \\
\text { (SD) }\end{array}$ & $\begin{array}{l}4.6 ; 5.0 \\
( \pm 3.3)\end{array}$ & $3.9 ; 4.0( \pm 3.2)$ & $\begin{array}{l}3.9 ; 4.0 \\
( \pm 3.4)\end{array}$ & $\begin{array}{l}6.6 ; 6.0 \\
( \pm 2.7)\end{array}$ & $5.5 ; 6.0( \pm 2.5)$ \\
\hline
\end{tabular}


Citation: Antoinette C (2018) Assessment of the"Post-Acute Care Discharge Scores"(PACD) [Translated from the Original Article in German Published in Pflegewissenschaft 2015; 11: 582-95]. J Nurs Care 7: 468. doi:10.4172/2167-1168.1000468

Page 7 of 11

\begin{tabular}{|l|l|l|l|l|l|}
\hline Nursing complications, number (\%) & $68(18.4 \%)$ & $14(10.6 \%)$ & $25(20.0 \%)$ & $19(25.3 \%)$ & $10(27.0 \%)$ \\
\hline Death during hospital stay, number (\%) & $18(4.9 \%)$ & $2(1.5 \%)$ & $5(3.9 \%)$ & $7(9.3 \%)$ & $4(10.8 \%)$ \\
\hline Confusion, number (\%) & $33(8.9 \%)$ & $4(3.0 \%)$ & $21(16.7 \%)$ & $3(4.0 \%)$ & $5(13.5 \%)$ \\
\hline $\begin{array}{l}\text { Independent with bathing or taking a shower } \\
\text { day 3, number (\%) }\end{array}$ & $146(55.3 \%)$ & $30(44.8 \%)$ & $51(54.3 \%)$ & $39(54.9 \%)$ & $26(81.3 \%)$ \\
\hline Independent transferring day 3, number (\%) & $84(31.8 \%)$ & $13(19.4 \%)$ & $34(36.2 \%)$ & $21(29.6 \%)$ & $16(50.0 \%)$ \\
\hline "SPI: the higher the score, the more independent. Minimum 10, maximum 40. & & \\
\hline
\end{tabular}

Table 3: Clinical characteristics; total patients.

The average PACD-Score on day-1 was considerably higher in fall patients than in patients with one of the other evaluated diseases (Table 4).

The majority of patients $(77.7 \%)$ were discharged home, $11.3 \%$ were discharged to a nursing home, $3.4 \%$ to temporary care, $2.8 \%$ to other places, $2.3 \%$ to rehabilitation, $2.0 \%$ to another hospital and $0.6 \%$ to health resort treatment. Most of the patients discharged home had syncopes and most of the patients discharged to a post-discharge care institution (rehabilitation, health resort, temporary care or nursing homes) experienced falls (Table 5).

\section{Diagnostic key figures}

With a sensitivity of $90 \%$, the PACD day- 1 Score $\geq 8$ points was more sensitive ( $62 \%$ specificity) than the score $\geq 8$ day- 3 with $80 \%$ (60\% specificity) (Table 6). In all cases, the PACD showed the best sensitivity with a cut-off $\geq 8$. With cut-offs $>8$ or $>9$ the specificity was higher which consequently caused a decrease in the sensitivity.

The accuracy related to transfer in a post-acute institution was good on day-1 and day-3 (AUC: 0.82-0.87 and AUC: 0.79-0.81 respectively). The PACD version day-1 reached the maximum accuracy (AUC 0.87) in the whole group of patients (Figure 3).

\begin{tabular}{|c|c|c|c|c|c|}
\hline & $\begin{array}{l}\text { Patients } \quad \text { total } \\
(n=371)\end{array}$ & $\begin{array}{l}\text { Syncope } \\
(n=132)\end{array}$ & $\begin{array}{l}\text { Urinary tract infection } \\
(n=127)\end{array}$ & $\begin{array}{ll}\begin{array}{l}\text { Congestive } \\
\text { failure }(n=75)\end{array} & \text { heart }\end{array}$ & Fall $(n=37)$ \\
\hline $\begin{array}{l}\text { PACD-Score* day } 1 ; \\
\text { Mean; Median (SD) }\end{array}$ & $\begin{array}{l}8.4 ; 7.0 \\
( \pm 5.8)\end{array}$ & $6.2 ; 5.0( \pm 4.9)$ & $\begin{array}{l}8.2 ; 6.0 \\
( \pm 6.0)\end{array}$ & $\begin{array}{l}9.9 ; 9.0 \\
( \pm 5.2)\end{array}$ & $13.5 ; 13.0( \pm 5.1)$ \\
\hline $\begin{array}{l}\text { PACD-Score* day } 3 \\
\text { Mean; Median (SD) }\end{array}$ & $\begin{array}{l}9.0 ; 8.0 \\
( \pm 5.5)\end{array}$ & $\begin{array}{l}7.8 ; 6.0 \\
( \pm 5.1)\end{array}$ & $\begin{array}{l}8.9 ; 7.0 \\
( \pm 5.8)\end{array}$ & $\begin{array}{l}8.5 ; 7.0 \\
( \pm 5.2)\end{array}$ & $\begin{array}{l}13.3 ; 14.5 \\
( \pm 4.5)\end{array}$ \\
\hline
\end{tabular}

Table 4: PACD Scores.

\begin{tabular}{|c|c|c|c|c|c|}
\hline & Patients total $(n=371)$ & Syncope $(n=132)$ & $\begin{array}{l}\text { Urinary tract } \\
\text { infection }(n=127)\end{array}$ & $\begin{array}{l}\text { Congestive } \\
\text { failure }(n=75)\end{array}$ & Fall $(n=37)$ \\
\hline \multicolumn{6}{|l|}{ Discharge locations, number (\%) } \\
\hline At home & $275(77.7 \%)$ & $117(90.0 \%)$ & $92(75.4 \%)$ & $50(72.5 \%)$ & $16(48.5 \%)$ \\
\hline Rehabilitation & $8(2.3 \%)$ & $2(1.5 \%)$ & $1(0.8 \%)$ & $3(4.3 \%)$ & $2(6.1 \%)$ \\
\hline Health resort treatment & $2(0.6 \%)$ & $1(0.8 \%)$ & - & - & $1(3.0 \%)$ \\
\hline Temporary care & $12(3.4 \%)$ & $3(2.3 \%)$ & $2(1.6 \%)$ & $3(4.3 \%)$ & $4(12.1 \%)$ \\
\hline Nursing home & $40(11.3 \%)$ & $3(2.3 \%)$ & $19(15.6 \%)$ & $8(11.6 \%)$ & $10(30.3 \%)$ \\
\hline Other hospital & $7(2.0 \%)$ & $3(2.3 \%)$ & $1(0.8 \%)$ & $3(4.3 \%)$ & - \\
\hline $\begin{array}{l}\text { Other location, e.g. geriatric } \\
\text { apartment }\end{array}$ & $10(2.8 \%)$ & $1(0.8 \%)$ & $7(5.7 \%)$ & $2(2.9 \%)$ & - \\
\hline
\end{tabular}

Table 5: Discharge locations. 
Page 8 of 11

\section{Discussion}

The aim of the study was to illustrate the ability of the PACD to identify post-acute care needs. The diagnostic value of the PACDs for risk identification showed the following three main points. The screening quality of the PACD on day-1 is high with a sensitivity of $90 \%$. The main criterion to evaluate the screening ability of PACD is the high sensitivity, as the instrument is intended to be used for screening purposes. As expected, the instrument showed lower specificity, however it is considered high enough for the instrument intended purpose. The specificity reached almost $70 \%$ and therefore lies near the recommended range for screening tests. As a global measurement, the AUC confirmed the benefits of systematic estimation.

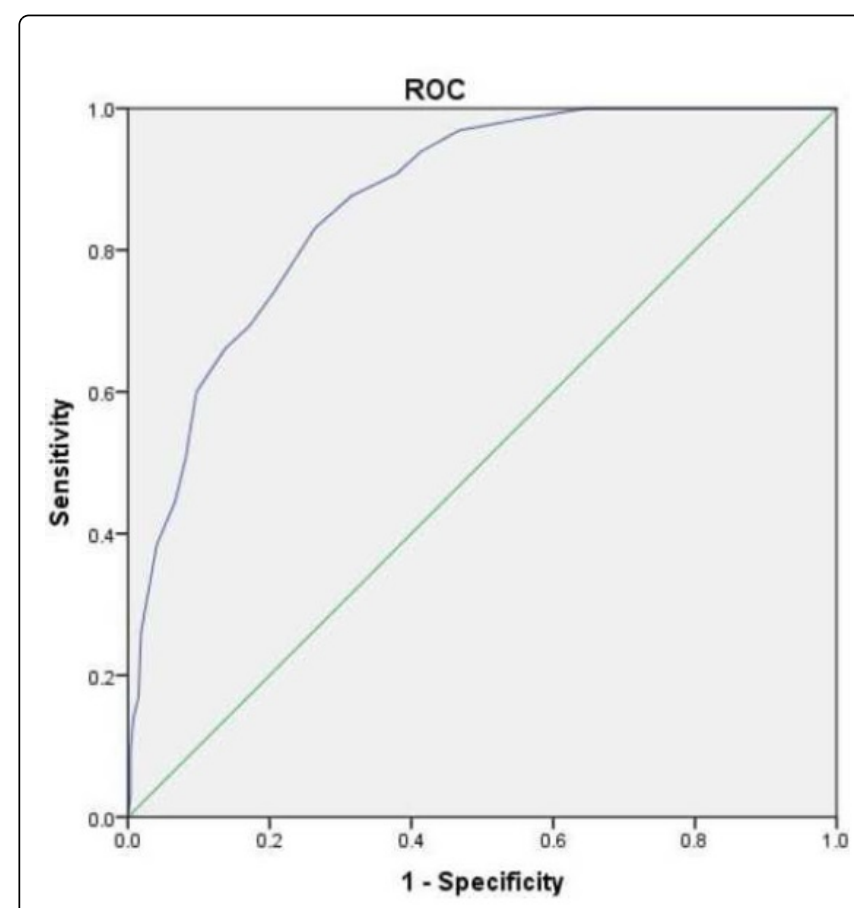

Figure 3: ROC curve PACD day 1; total patients.
The current study showed slightly lower sensitivity and specificity ( $80 \%$ and $60 \%$ respectively) on day-3 compared to the values of the Geneva PACD scores: sensitivity $87 \%$ and specificity 63\% [5]. Moreover, the AUC-values of day-1 (AUC: 0.82 vs. AUC Geneva: 0.81) and the values of day-3 (AUC: 0.79 vs. AUC Geneva: 0.82) were similar [5]. The overall relatively small differences in day- 1 could be attributed to the age factor - weighted 60 years and above - and to the exclusion of the item "transfer within the hospital".

The results of the first project phase OPTIMA I [33] confirmed a significant relationship between the risk of post-acute care needs of patients with respiratory tract infections and transfer destination, which could also be shown in the Geneva version [5]. In the more extended diagnosis groups of OPTIMA II, the estimation of biopsychosocial risks showed sensitivity and specificity similar to that of the respiratory tract infection patients, hence a potential additional benefit to the discharge organization.

\section{Strengths and limitations}

As recommended in the expert standard [16], in Bowles et al. [18] and in Holland et al. [19], the PACD-with its good sensitivity and specificity values-can be used as a standardized assessment instrument to early identify patients with post-acute care needs. The PACD data can be collected mainly by nurses, which is in accordance with the expert standards [16]. The physicians' role with the PACD is limited to the assessment of the medically active problems. Data collection is tested in the clinical context and has been proven feasible.

Some limitations of the study need to be addressed. Data were not collected from $11(3 \%)$ of the potential patients at admission or during their hospital stay due to the poor general condition of the patients, the need for intensive medical treatment or patients' refusal to participate in the study. Furthermore, the lack of distinct documentation resulted in missing data. Whether a patient was transferred from a nursing or elderly home to the hospital was not differentiated. Most of the elderly homes in Switzerland have an integrated nursing ward and are therefore similar to nursing homes. A possible bias is therefore improbable.

\begin{tabular}{|c|c|c|c|}
\hline Cut-off & $\geq 8$ & $>8$ & $>9$ \\
\hline \multicolumn{4}{|c|}{ PACD day 1} \\
\hline \multicolumn{4}{|c|}{ Patients total $(n=3341)$} \\
\hline Sensitivity & $91 \%$ & $88 \%$ & \\
\hline Specificity & $62 \%$ & $68 \%$ & \\
\hline \multicolumn{4}{|l|}{ AUC: 0.87} \\
\hline \multicolumn{4}{|c|}{ Hospital admission from home $(n=308)$} \\
\hline Sensitivity & $90 \%$ & $86 \%$ & \\
\hline Specificity & $62 \%$ & $68 \%$ & \\
\hline AUC: 0.85 & & & \\
\hline
\end{tabular}




\begin{tabular}{|c|c|c|c|}
\hline \multicolumn{4}{|c|}{ Without ambulatory Patients and Patients without admitted from institution $(n=233)$} \\
\hline \multicolumn{2}{|l|}{ Sensitivity } & \multirow[b]{2}{*}{$88 \%$} & \multirow[b]{2}{*}{$80 \%$} \\
\hline Specificity & $93 \%$ & & \\
\hline AUC: 0.82 & $51 \%$ & $59 \%$ & $65 \%$ \\
\hline \multicolumn{2}{|c|}{ PACD day 3} & & \\
\hline \multicolumn{3}{|c|}{ Patients total $(n=246)$} & \\
\hline Sensitivity & $82 \%$ & $79 \%$ & \\
\hline Specificity & $61 \%$ & $64 \%$ & \\
\hline \multicolumn{4}{|l|}{ AUC: 0.81} \\
\hline \multicolumn{4}{|c|}{ Hospital admission from home $(n=220)$} \\
\hline Sensitivity & $80 \%$ & $76 \%$ & \\
\hline Specificity & $60 \%$ & $64 \%$ & \\
\hline AUC: 0.79 & & & \\
\hline
\end{tabular}

Table 6: Diagnostic key figures.

Furthermore, data were collected by nurses at the INZ and on the ward. Although it probably was less standardized than that carried out by the study team, it was integrated in the clinical routine. Overall, this did not seem to be a significant problem, as only $10 \%$ of the data on day- 1 and day- 3 which should have been identical were documented differently. It is therefore to be assumed that the application of the instrument in the daily routine without monitoring by the study team gets less precise and causes more variable data. However, an enhanced precision is expected with progressively gained skills. The collected PACD scores were not blinded. They were accessible in the electronic patient system (day-3) and the paper documentation of the INZ (day-1) was stored in the medical history. It is therefore possible, that the decision of nurses and physicians to transfer patients to post-acute care institutions was based on the scores of the collected data.

The wide spectrum of the medical diagnosis (urinary tract infection, congestive heart failure, fall and syncope) which bears differences in the need for support, independence and social situation could have caused slight distorted positive diagnostic values (sensitivity/ specificity). A misclassification in the direction of false positive rate (lower specificity) was taken into account because the aim was to reach high sensitivity. Another limitation related to the transfer to a postacute care institution was the inability to check whether such an institution was the most suitable discharge destination. The collected data showed merely the discharge destination.

\section{Conclusion}

Although the studied patient group did not represent the whole spectrum of medical patients, it is recommended to use the PACD version of day-1 in order to start the discharge plan early. PACD day-1 might be more effective than day-3 because it allows for more time to plan the discharge and to involve the social worker at an early stage if needed. The sensitivity of day-1 was slightly higher than that of day-3. To have the emergency team, as pioneers in Switzerland, identifying extraordinarily early and systematically patients at risk seems at the first glance unfamiliar. Therefore, the health care team, especially nurses is required to understand the importance of the collected information and be able to interpret it and put it into action. In such a way, it would be possible to early identify post-acute nursing and care deficits, to set early and structured priorities, to allow nurses and physicians to analyse the situation together and to be able to react appropriately. On the one hand, a targeted assessment of the situation is important for an early discharge plan. On the other hand, it is important to involve the social workers and the physiotherapists, plan and reevaluate the required interventions for the discharge as recommended by Simonet et al. [5].

\section{Future studies should:}

- Evaluate the screening qualities of the PACD in a non-selective and larger sample of medical patients.

- Evaluate the prediction power of the PACD on the longtime course to include re-hospitalization and development of individual nursing care needs.

- Test the combination of PACD with other social, clinical information and/or laboratory biomarkers regarding prediction improvement.

- Directly compare the PACD with other screening instruments, for example, SWAAT, BRASS-Index or SPI.

- Verify the potential for process optimization by application of the screening to allow automatic referral to the social worker in a discharge-oriented case management as part of an intervention study.

- Verify whether the discharge destination was retrospectively the most suitable for the patient.

In the OPTIMA Phase 3, a multi-professional communication platform would be developed. The so-called "ward round tool" [38] 
integrates the PACD systematically in patient evaluation and discussion of discharge plan during physician-nurse rounding. This would foster close collaboration between physicians, nurses and social workers. The information in the PACD about the availability and need of care or assistance at home gives the social services a prompt picture of the possible care needs. This study provided the prerequisites to develop general standards to optimize the patient process in the medical university clinic and in the whole hospital. This, in accord with the recommendation of Ackerly et al. [39] supports the development of new models of coordination between acute and post-acute care that are team-based and patient-oriented through the exchange of clinical and social information in a shared information technology.

The application of post-acute nursing care needs estimation will be further studied and evaluated. Furthermore, data of a bigger sample of medical inpatients at our university clinic will be collected 2012-2013 to re-evaluate the diagnostic characteristics of the PACD. The analysis of these data would show whether the PACD can be applied to all medical patients and which point of time is the most significant to collect the score.

\section{Acknowledgement}

Support was received by the research council-"Forschungsrat" of the Kantonsspital Aarau (project number 1410.000.003) and the Department of Health and Social Services of the Canton Aargau, Switzerland. The author thanks the following people for their help and support: Angela Gabele, Katharina Regez, Corinne Brunner, Ursula Schild, Merih Guglielmetti, Sherin Sebastian, Petra Schäfer-Keller, Susanne Schirlo, Ruth Schweingruber, Barbara Reutlinger, Petra Tobias, Ulrich Bürgi, Kristina Rüegger, Andreas Huber, Alexander Litke, Birsen Arici, Frank Dusemund, Claudine A. Blum, Philipp Schütz, Beat Müller, and Werner C. Albrich.

\section{References}

1. http://www.swissworld.org/de/bevoelkerung/bevoelkerungstrends.html

2. http://www.euro.who.int/document/E82970.pdf

3. Gill TM, Allore HG, Holford TR, Guo Z (2004) Hospitalization, restricted activity, and the development of disability among older persons. JAMA 292: 2115-2124.

4. Labarere J, Stone RA, Scott OD, Yealy DM, Meehan TP, et al. (2006) Factors associated with the hospitalization of low-risk patients with community-acquired pneumonia in a cluster-randomized trial. J Gen Intern Med 21: 745-752.

5. Louis SM, Kossovsky MP, Chopard P, Sigaud P, Perneger TV, et al. (2008) A predictive score to identify hospitalized patients' risk of discharge to a post-acute care facility. BMC Health Serv Res 8: 154.

6. Boutin-Foster C, Euster S, Rolon Y, Motal A, BeLue R, et al. (2005) Social Work Admission Assessment Tool for identifying patients in need of comprehensive social work evaluation. Health Soc Work 30: 117-125.

7. Albrich WC, Ruegger K, Dusemund F, Bossart R, Regez K, et al. (2011) Optimised patient transfer using an innovative multidisciplinary assessment in Kanton Aargau (OPTIMA I): an observational survey in lower respiratory tract infections. Swiss Med Wkly 141: w13237.

8. Albrich WC, Ruegger K, Dusemund F, Schuetz P, Arici B, et al. (2013) Biomarker-enhanced triage in respiratory infections: a proof-of-concept feasibility trial. Eur Respir J 42: 1064-1075.

9. Dusemund F, Steiner M, Vuilliomenet A, Muller C, Bossart R, et al. (2012) Multidisciplinary assessment to personalize length of stay in acute decompensated heart failure (OPTIMA II ADHF). J Clin Med Res 4: 402-409.
10. Baehni C, Meier S, Spreiter P, Schild U, Regez K, et al. (2010) Which patients with lower respiratory tract infections need inpatient treatment? Perceptions of physicians, nurses, patients and relatives. BMC Pulm Med 10: 12 .

11. Spreiter P, Meier S, Baehni C, Schild U, Regez K, et al. (2010) Steps to take to reduce length of hospital stay in patients with lower respiratory tract infections: a prospective cohort study. Home Health Care Manag Pract 27: 184-191.

12. Fortinsky RH, Covinsky K, Palmer RM, Landefeld CS (1999) Effects of functional status changes before and during hospitalization on nursing home admission of older adults. J Gerontol A Biol Sci Med Sci 54A: 521-526.

13. Fried TR, Mor V (1997) Frailty and hospitalization of long-term stay nursing home residents. J Am Geriatr Soc 45: 265-269.

14. Covinsky KE, Pierluissi E, Johnston CB (2011) Hospitalization-associated disability: "She was probably able to ambulate, but I'm not sure". JAMA 306: 1782-1793.

15. Boyd CM, Landefeld CS, Counsell SR, Palmer RM, Fortinsky RH, et al. (2008) Recovery of activities of daily living in older adults after hospitalization for acute medical illness. J Am Geriatr Soc 56: 2171-2179.

16. DNQP (2009) Expertenstandard Entlassungsmanangement in der Pflege. Hochschule Osanbrück, Osnabrück.

17. http://www.bmg.gv.at/cms/home/attachments/1/3/0/CH1333/ CMS1350910195632/bqll_aufem_materialiensammlung_2012.pdf

18. Bowles KH, Ratcliffe SJ, Holmes JH, Liberatore M, Nydick R, et al. (2008) Post-acute referral decisions made by multidisciplinary experts compared to hospital clinicians and the patients' 12-week outcomes. Med Care 46: 158-166.

19. Holland DE, Mistiaen P, Bowles KH (2011) Problems and unmet needs of patients discharged "home to self-care". Prof Case Manag 16: 240-250.

20. Bauer M, Fitzgerald L, Haesler E, Manfrin M (2009) Hospital discharge planning for frail older people and their family. Are we delivering best practice? A review of the evidence. J Clin Nurs 18: 2539-2546.

21. Naylor MD, Brooten D, Campbell R, Jacobsen BS, Mezey MD, et al. (1999) Comprehensive discharge planning and home follow-up of hospitalized elders: A randomized clinical trial. JAMA 281: 613-620.

22. Naylor MD, Brooten D, Campbell R, Jacobsen BS, Mezey MD, et al. (2004) Transitional care of older adults hospitalized with heart failure: a randomized, controlled trial. J Am Geriatr Soc 52: 675-684.

23. Shepperd S, McClaran J, Phillips CO, Lannin NA, Clemson LM, et al. (2010) Discharge planning from hospital to home. Cochrane Database Syst Rev Jan 20: CD000313.

24. Campbell SE, Seymour DG, Primrose WR, Lynch JE, Dunstan E, et al. (2005) A multi-centre European study of factors affecting the discharge destination of older people admitted to hospital: analysis of in-hospital data from the ACMEplus project. Age Ageing 34: 467-475.

25. Rudberg MA, Sager MA, Zhang J (1996) Risk factors for nursing home use after hospitalization for medical illness. J Gerontol Biol Sci Med Sci 51: M189-94.

26. Cornette P, Swine C, Malhomme B, Gillet JB, Meert P, et al. (2006) Early evaluation of the risk of functional decline following hospitalization of older patients: Development of a predictive tool. Eur J Public Health 16: 203-208.

27. Hoogerduijn JG, Schuurmans MJ, Duijnstee MS, de Rooij SE, Grypdonck MF (2007) A systematic review of predictors and screening instruments to identify older hospitalized patients at risk for functional decline. J Clin Nurs 16: 46-57.

28. http://www.epacc.de/files/content/Downloads/ Schlarmann_MASTERARBEIT_public.pdf

29. Mistiaen P, Duijnhouwer E, Prins-Hoekstra A, Ros W, Blaylock A (1999) Predictive validity of the BRASS index in screening patients with postdischarge problems. Blaylock Risk Assessment Screening Score. J Adv Nurs 30: 1050-1056.

30. Panella L, La Porta F, Caselli S, Marchisio S, Tennant A (2012) Predicting the need for institutional care shortly after admission to rehabilitation: 
Citation: Antoinette C (2018) Assessment of the"Post-Acute Care Discharge Scores"(PACD) [Translated from the Original Article in German Published in Pflegewissenschaft 2015; 11: 582-95]. J Nurs Care 7: 468. doi:10.4172/2167-1168.1000468

Page 11 of 11

Rasch analysis and predictive validity of the BRASS Index. Eur J Phys Rehabil Med 48: 443-454.

31. Hoogerduijn JG, Schuurmans MJ, Korevaar JC, Buurman BM, de Rooij SE (2010) Identification of older hospitalised patients at risk for functional decline, a study to compare the predictive values of three screening instruments. J Clin Nurs 19: 1219-1225.

32. Conca A, Regez K, Schild U, Reutlinger B, Schafer P, et al. (2013) At admission planning discharge already. Krankenpfl Soins Infirm 106: 20-23.

33. Conca A, Bossart R, Regez K, Schild U, Wallimann G, et al. (2012) OPTIMA-Optimierter patienten-transfer durch innovatives multidisziplinäres Assessment. Projektbeschreibung der Phase I. Pflegewissenschaft 14: 291-298.

34. Knottnerus JA, van Weel C, Muris, JW (2002) Evaluation of diagnostic procedures. BMJ 324: 477-480.
35. http://www2.aap.org/sections/dbpeds/pdf/Standards\%20for \%20Screening\%20Test\%20Construction.pdf

36. SPSS Inc (2007) SPSS for Windows, Version 16.0. Chicago.

37. Litke A, Bossart R, Regez K, Schild U, Guglielmetti M, et al. (2013) The potential impact of biomarker-guided triage decisions for patients with urinary tract infections. Infection 41: 799-809.

38. Schuetz P, Hausfater P, Amin D, Haubitz S, Faessler L, et al. (2013) Optimizing triage and hospitalization in adult general medical emergency patients: the triage project. BMC Emerg Med 13: 12.

39. Ackerly DC, Grabowski DC (2014) Post-acute care reform -beyond the ACA. N Engl J Med 370: 689-697. 